\title{
ONLINE MOODLE SEBAGAI E-LEARNING BAGI SISWA SMK PESERTA PRAKTEK KERJA INDUSTRI
}

\author{
Akbar Mubarrak ${ }^{1)}$, Jaslin Ikhsan ${ }^{2)}$ \\ ${ }^{1}$ SMK Negeri 1 Purworejo \\ J1.Tentara Pelajar, Kotak Pos 127 Purworejo \\ akbarmubarrak@gmail.com \\ ${ }^{2}$ Jurdik. Kimia FIPA UNY \\ Karangmalang, Yogyakarta 55281 \\ jikhsan@uny.ac.id
}

\begin{abstract}
Abstrak: Penelitian ini bertujuan untuk mengintegrasikan TIK dalam bidang pendidikan dengan merancang dan mengaplikasikan online moodle sebagai e-learning bagi siswa kelas XII TKR.B SMK Negeri 1 Purworejo yang menjalani Praktek Kerja Industri (Prakerin) selama 3 bulan diluar sekolah. Peneliti menggunakan metode penelitian dan pengembangan (Research and Development) dan instructional design ADDIE dalam pengembangan e-learning. Hasil dari penelitian ini adalah perancangan dan penerapan online moodle sebagai media belajar jarak jauh atau e-learning bagi siswa Prakerin. Guru dapat mengunggah modul-modul pembelajaran dan memberikan test untuk mengetahui sejauh mana pemahaman siswa terhadap materi yang diberikan lewat modul. Online moodle dapat diakses oleh siswa kapanpun dan dimanapun mereka berada baik melalui handpone atau mengaksesnya di warung internet. Semua fasilitas yang ada didalam online moodle dengan mudah dapat digunakan sebagai media pembelajaran jarak jauh.
\end{abstract}

Kata kunci:e-learning, online moodle,Prakerin

\begin{abstract}
This study aims to integrate ICT by designing and applying online moodle as an elearning material for class XII TKR.B students of SMK Negeri 1 Purworejo who undergo On Job Training for three months. In developing the e-learning, researchers use Research and Development method and ADDIE instructional design. Result of this study is the design and implementation of moodle as online learning media for OJT students. Teachers can upload learning modules and provide a test to determine the extent of students' understanding of material provided by the module. Online moodle can be accessed by students anytime and anywhere, either from mobile phone or internet cafes. All facilities provided in online moodle can easily be used as a medium of distance learning.
\end{abstract}

Keywords: E-learning, online moodle, industrial internship

\section{PENDAHULUAN}

Sekolah Menengah Kejuruan (SMK) merupakan jenjang pendidikan menengah kejuruan yang mengutamakan pengembangan keterampilan peserta didik untuk melaksanakan jenis pendidikan tertentu yang bertujuan untuk 
mempersiapkan siswa agar memiliki keterampilan dan siap terjun ke dunia kerja. Berdasarkan hal tersebut dapat dikatakan bahwa sekolah menengah kejuruan merupakan lembaga pendidikan yang menjembatani dunia pendidikan dengan dunia kerja secara langsung sehingga pendidikan kejuruan menyediakan stimulasi berupa pengalaman belajar dan interaksi dengan dunia luar dari diri anak didik dalam mengembangkan potensinya untuk memasuki dunia kerja.

SMK merupakan lembaga pendidikan yang mempunyai karakteristik antara lain (Tuloli M.Y., 2006) :

1. SMK diarahkan untuk mempersiapkan peserta didik memasuki dunia kerja.

2. SMK didasarkan atas demand driven atau kebutuhan dunia kerja.

3. Fokus isi SMK ditekankan pada penguasaan pengetahuan, keterampilan, sikap dan nilai-nilai yang dibutuhkan dunia kerja.

4. Penilaian yang sesungguhnya terhadap kesuksesan peserta didik harus pada hands on atau performa dalam dunia kerja.

5. Hubungan yang erat dengan dunia kerja merupakan kunci sukses SMK.

6. SMK yang baik harus memiliki sifat responsif dan antisipatif terhadap kemajuan teknologi.

7. SMK lebih menekankan pada learning by doing dan hands on experience.

8. SMK memerlukan fasilitas mutakhir untuk kegiatan praktik.

9. SMK memerlukan biaya investasi dan operasional yang lebih besar dibandingkan SMA atau pendidikan umum lainnya.

Pelaksanaan pembelajaran di SMK dilakukan dengan cara pembelajaran learning by doing yang diimplementasikan dalam bentuk pelatihan di dunia kerja yang sering disebut dengan Pratek Kerja Industri (Prakerin). Prakerin adalah pelatihan di tempat kerja yang diselenggarakan dengan maksud membentuk kecakapan tenaga kerja yang diperlukan untuk suatu pekerjaan tertentu. Prakerin adalah suatu bentuk pembekalan yang dapat mempercepat proses pemindahan pengetahuan dan pengalaman kerja atau transfer knowledge. Pelatihan ini langsung menerjunkan peserta didik sesuai dengan job description atau jobdesc masing-masing di bawah pengawasan dan bimbingan (Sastrohadiwiryo S, 2003) 
Pelaksanaan prakerin merupakan bagian dari pendidikan sistem ganda yang merupakan inovasi pada program SMK dimana peserta didik melakukan praktek kerja (magang) di perusahaan atau industri yang merupakan bagian integral dari proses pendidikan dan pelatihan di SMK. Pendidikan Sistem Ganda (PSG) diilhami oleh dua sistem (dual system) yang dilakukan di Jerman. Mulai diberlakukan di Indonesia berdasarkan kurikulum SMK tahun 1994, dipertajam dengan kurikulum SMK edisi 1999 dan dipertegas dengan kurikulum SMK edisi 2004.

Penerapan Prakerin di SMK Negeri 1 Purworejo dilaksanakan oleh siswa kelas XII selama 3 bulan yaitu dari bulan Juni sampai September. Dipilihnya kelas XII bukan kelas XI untuk melakukan Prakerin karena kelas XII lebih matang baik secara skill maupun mental dan psikologinya sebab selama Prakerin siswa totalitas berada di industri yang lokasinya menyebar jauh diluar kota sehingga sulit bagi guru maupun orangtuanya untuk selalu mengontrolnya. Permasalahnya kemudian adalah ketika siswa tersebut telah menyelesaikan Prakerinnya, mereka ketinggalan materi belajar selama 2 bulan yaitu Juli dan September dan mereka juga harus mempersiapkan diri untuk menghadapi Ujian Akhir Nasional (UAN).

Memahami permasalahan tersebut, peneliti mencoba untuk memecahkan masalah di atas dengan mengintegrasikan pembelajaran dengan perkembangan teknologi informasi dan komunikasi (TIK). Peneliti merancang dan menerapkan online moodle sebagai e-learning sehingga guru tetap dapat memberikan materi pembelajaran, memberikan evaluasi, mengontrol dan memantau siswa ketika mereka menjalani Prakerin di luar kota. Para siswa dapat dengan mudah mengakses online moodle kapanpun dan dimanapun mereka berada baik dengan mengakses melalui handphone maupun di warung internet yang sekarang sudah banyak tersebar. Pengintegrasian pembelajaran dengan TIK dengan menerapkan online moodle diharapkan dapat melatih siswa yang sedang Prakerin untuk mampu belajar mandiri dan mengatur waktu antara praktek kerja di industri dengan belajar secara mandiri melalui online moodle. Peneliti membatasi penelitiannya hanya untuk mata pelajaran bahasa Inggris untuk siswa kelas XII TKR.B. 


\section{METODE}

Dalam penelitian ini, peneliti menggunakan metode Penelitian dan Pengembangan (Research and Development) dengan menggunakan instructional design ADDIE dalam pengembangan e-learning yang terdiri dari 5 tahap, yaitu:

Tahap 1: Analisis (Analysis)

Tahap analisis merupakan suatu proses mendefinisikan materi apa saja yang akan disajikan untuk dipelajari oleh siswa dalam e-learning. Untuk mengetahui atau menentukan apa yang harus dipelajari, peneliti melakukan beberapa kegiatan, diantaranya adalah melakukan needs assessment (analisis kebutuhan), mengidentifikasi masalah (kebutuhan), dan melakukan analisis tugas (task analysis).

Tahap 2: Desain (Design)

Tahap ini dikenal juga dengan istilah membuat rancangan (blue-print) dengan merumuskan tujuan pembelajaran yang SMAR (Specific, Measurable, Applicable, dan Realistic). Selanjutnya menyusun materi dan evaluasi untuk mengetahui sejauh mana pemahaman siswa terhadap materi yang diberikan. Dalam tahapan ini peneliti juga mendesain layout dan fasilitas-fasilitas yang ada di dalam moodle sehingga navigasinya mudah digunakan oleh siswa dan mudah untuk diakses baik dengan menggunakan handphone maupun menggunakan komputer.

\section{Langkah 3: Pengembangan (Development)}

Tahap ini adalah proses mewujudkan blue-print menjadi suatu produk yaitu online moodle yang digunakan oleh siswa Prakerin sebagai e-learning. Pengembangan dibagi menjadi 2 kategori, yaitu pengembangan materi pembelajaran beserta evaluasinya dan pengembangan layout dan fasilitas-fasilitas yang ada di dalam moodle.

Langkah 4: Implementasi (Implementation)

Dalam tahap ini online moodle sudah dapat di implementasikan dan dapat dilakukan uji coba dalam skala kecil untuk mendapatkan feedback guna penyempurnaan online moodle. 


\section{Langkah 5: Evaluasi (Evaluation)}

Tahap ini adalah proses untuk melihat apakah online moodle yang telah diaplikasikan telah sesuai dengan apa yang telah di rencanakan atau tidak. Evaluasi bisa terjadi pada setiap empat tahap di atas. Evaluasi yang terjadi pada setiap empat tahap diatas dinamakan evaluasi formatif, karena tujuannya untuk kebutuhan revisi semisal review ahli untuk memberikan input terhadap online moodle yang telah dibuat.

\section{HASIL PENELITIAN}

Berikut ini disajikan uraian pelaksanakan dan hasil penelitian dan pengembangan mengikuti ADDIE Model.

\section{Tahap 1: Analisis (Analysis)}

Model Kurikulum Tingkat Satuan Pendidikan (KTSP) yang diterapkan oleh SMK Negeri 1 Purworejo untuk mata pelajaran bahasa Inggris kelas XII dengan standar kompetensi berkomunikasi dengan Bahasa Inggris setara Level Intermediate memiliki 6 kompetensi dasar. Dalam penelitian ini, peneliti hanya mengambil 2 kompetensi dasar untuk diuji cobakan dalam e-learning mengingat selama siswa menjalankan Prakerin mereka akan ketinggalan materi 2 kompetensi dasar. Melihat tebaran lokasi Prakerin yang kebanyakan ada di Jawa Barat, Jawa Tengah dan Jawa Timur serta laporan dari beberapa siswa pada saat melakukan survey ke tempat Prakerin yang menyatakan bahwa mereka jarang menjumpai warnet di dekat lokasi kost mereka maka e-learning harus dapat diakses melalui handphone siswa yang kebetulan setiap siswa telah mempunyai handphone yang sudah terinstall operamini untuk mengakses internet.

\section{Tahap 2: Desain (Design)}

Peneliti mendesain modul yang nantinya akan di download oleh siswa sebagai bahan bacan sekaligus juga menyusun perangkat untuk evaluasi siswa. Dalam tahapan ini peneliti selalu melakukan konsultasi dan review dengan beberapa guru bahasa Inggris di SMK Negeri 1 Purworejo. 
Peneliti juga mendesain layout tampilan moodle dengan menempatkan beberapa menu baik di kanan maupun di kiri tampilan moodle agar navigasinya mudah dan tidak membingungkan siswa.

\section{Tahap 3: Pengembangan (Development)}

Setelah beberapa kali direview dan direvisi oleh beberapa guru bahasa Inggris, modul beserta evaluasinya di kemas ke dalam online moodle dengan menggunakan domain www.pakakbar.tk. Layout online moodle dibuat sedemikian rupa agar siswa mudah memahami apa yang harus mereka lakukan

\begin{tabular}{|ll|}
\hline Available courses & Here you will find interesting materials about English for Vocational \\
Course for class XII & $\begin{array}{l}\text { School for class XII. All materials here are easy to understand and } \\
\text { fun because I provide you with handout, picture, sound and also } \\
\text { video in every topic. } \\
\text { So...what are you waiting for? }\end{array}$
\end{tabular}

Gambar 1. Tampilan pelajaran yang tersedia di dalam moodle

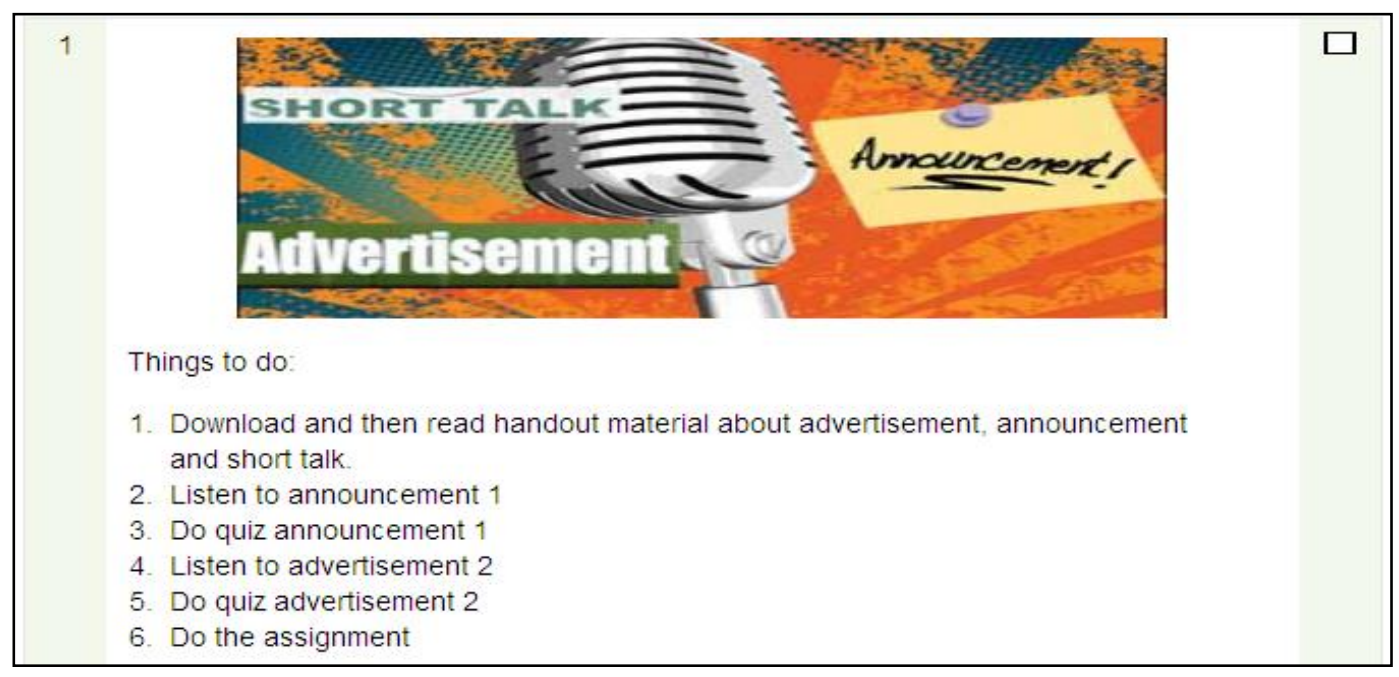

Gambar 2.Tampilan dalam moodle untuk kompetensi dasar memahami monolog yang muncul pada situasi kerja tertentu 


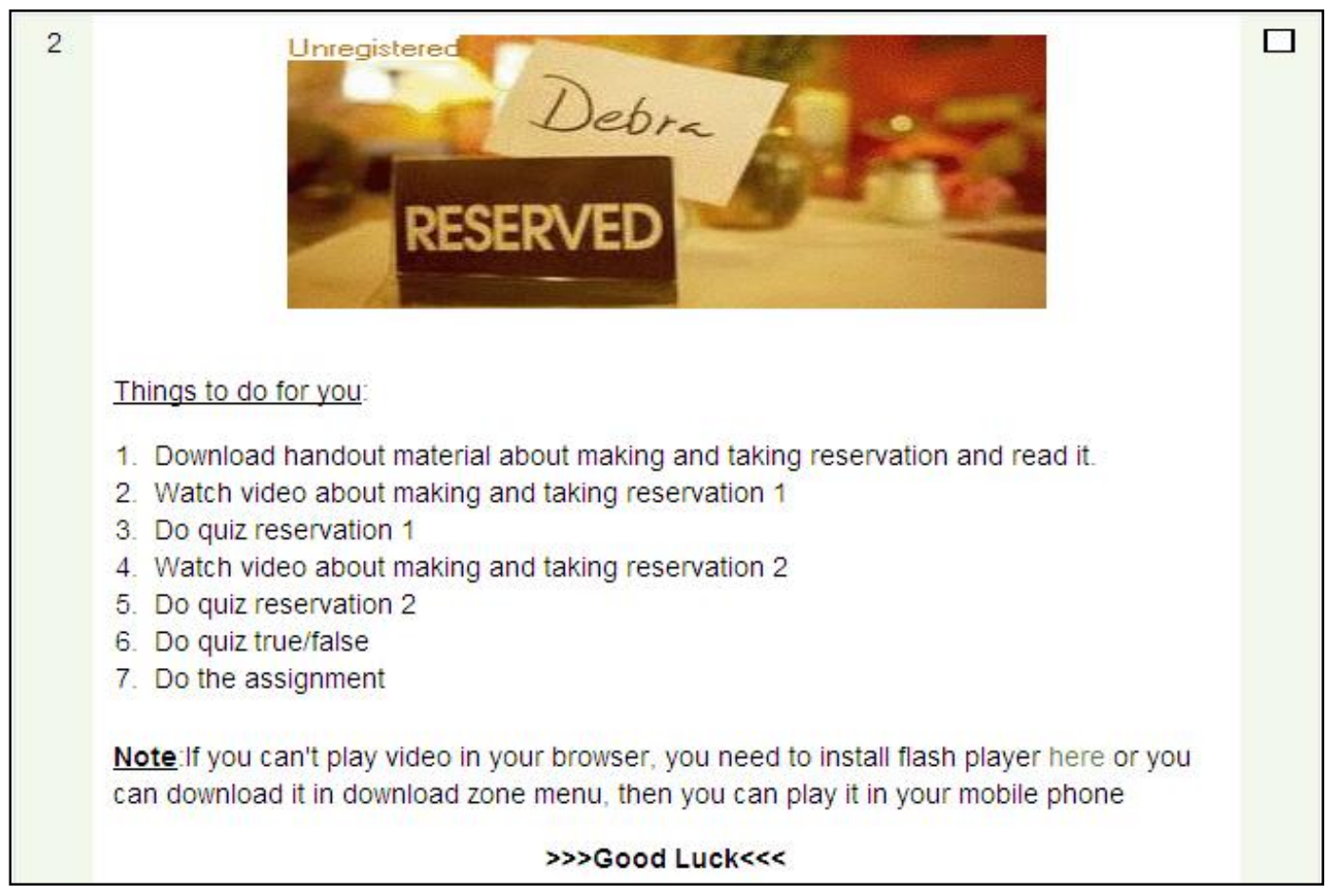

Gambar 3.Tampilan dalam moodle untuk kompetensi dasar Memahami percakapan terbatas dengan penutur asli.

\section{Tahap 4: Implementasi (Implementation)}

Prototype online moodle yang sudah dikembangkan perlu di implementasikan untuk diujicobakan kepada siswa baik diakses dengan menggunakan komputer yang terkoneksi dengan internet maupun dengan menggunakan handphone dengan menggunakan browser opera mini .

\section{Langkah 5: Evaluasi (Evaluation)}

Setelah di ujicobakan ternyata ada beberapa fitur video yang diletakan pada kuis tidak dapat dibuka jika diakses dengan menggunakan handphone, padahal video ini mempunyai peranan yang penting dalam menjawab pertanyaannya dengan benar. Untuk mengatasi hal ini, peneliti memberikan menu download untuk mendownload videonya yang dikemas dalam format $3 \mathrm{gp}$ sehingga video dapat dilihat dengan menggunakan handphone.

Dalam proses ujicoba ternyata juga ditemukan error pada database, temuan ini dilaporkan oleh salah seorang siswa saat mencoba login untuk mengerjakan kuis. Namun tidak lama setelah peneliti mencoba memperbaiki error pada database, online moodle dapat akses kembali. 


\section{GP Movie}

Reservation 1

Reservation 2

Gambar 5.Menu download 3gp movie

Error reading from database

Coding error detected, it must be fixed by a programmer: block_manager has not yet loaded the blocks, to it is too soon to request the information you asked for.

Gambar 4.Error pada database

\section{PEMBAHASAN}

Pengintegrasikan TIK dengan dunia pendidikan terutama dalam bidang pendidikan jarak jauh dengan menggunakan online moodle sebagai E-learning yang diterapkan kepada siswa kelas XII TKR.B SMK Negeri 1 Purworejo ternyata menimbulkan dampak, baik itu positif maupun negatif.

Dampak yang positif dari penggunaan online moodle bagi siswa yang sedang menjalankan praktek kerja industri terlihat dari pencapaian nilai yang sangat memuaskan saat mereka mengerjakan kuis yang disajikan dalam online moodle. Hal ini menunjukan kecakapan mereka dalam belajar mandiri serta mengatur waktu antara belajar dari modul yang diberikan di online moodle dan praktek di industri. Kuis yang diberikan dalam online moodle tidak akan dapat dijawab dengan benar jika siswa tidak belajar terlebih dahulu dari modul, selain itu siswa juga tidak akan dapat mencontek temannya karena setiap pertanyaan dan juga butir jawaban akan selalu berubah secara acak. Penguasaan materi siswa 
yang sangat baik juga dilaporkan oleh guru yang mengajar siswa kelas XII TKR.B kepada peneliti. Hal ini dibuktikan dari hasil ulangan yang dikerjakan siswa saat mereka selesai menjalani Prakerin dan kembali ke sekolah.

Pelaksanaan online moodle sebagai e-learning bagi siswa yang sedang melaksanakan Prakerin ternyata juga membuat beberapa siswa mengalami defisit anggaran terutama bagi siswa yang mengakses e-learning melalui handphone. Peneliti juga mendapatkan laporan dari mandor perusahaan yang mengatakan bahwa siswa terkadang ijin tidak masuk dengan alasan mengerjakan kuis.

\section{KESIMPULAN}

Hasil penelitian dari penerapan online moodle sebagai e-learning saat siswa kelas XII TKR.B SMK Negeri 1 Purworejo menjalankan Prakerin merupakan jalan keluar agar siswa tetap bisa menerima materi pelajaran dan melaksanakan evaluasi disaat mereka harus menjalankan praktek kerja industri yang lokasinya jauh dari sekolah dan menyebar diberbagai kota.

Karakteristik e-learning yang menuntut siswa untuk belajar mandiri ternyata telah membentuk karakter siswa untuk lebih mandiri dalam belajar dan pandai mengatur waktu sehingga dari hasil penelitian ini terlihat siswa lebih siap dalam menghadapi Ujian Akhir Nasional (UAN).

\section{UCAPAN TERIMA KASIH}

Peneliti mengucapkan terima kasih kepada SEAMOLEC yang telah memberikan beasiswa S2 dan bimbingan dalam penelitian ini. Peneliti juga mengucapkan terima kasih kepada kepala sekolah dan guru-guru di SMK Negeri 1 Purworejo yang telah memberikan ijin dan membantu dalam pelaksanaan penelitian. 


\section{DAFTAR PUSTAKA}

Borg, Walter R, and Gall (1979), Educational Research ; An Introduction.New York: Longman

Dick \& Carey. (2010), ADDIE Model. diakses pada tanggal 17November 2011 dari: http://www.learning-theories.com/addie-model.html

Jason Cole dan Helen Foster (2007), Using Moodle. O'Reilly Media, Inc. Cambridge.

Newby, J Timothy at all. (2006), Educational Technology for Teaching and Learning. Ohio: Pearson Merrill Prentice Hall.

Tutoli, M.Y. (2006), Administrasi dan Supervisi Pendidikan Nasional. Jakarta: Ghalia Indonesia.

Sastrohadiwiryo S. (2003), Manajemen Tenaga Kerja Indonesia: Pendekatan Administratif dan Operasional. Jakarta: PT Bumi Aksara. 